\title{
The Study of Phytochemical Analysis of Cynodon dactylon Leaves Extract on Albino Rats
}

\author{
Brindha. $\mathbf{P}^{1}$, Ilanchezhian. $\mathbf{T}^{* 2}$, Manju Bhargavi. $\mathbf{A}^{\mathbf{1}}$, Kowsalya. $\mathbf{K}^{\mathbf{3}}$ \\ ${ }^{1}$ Mphil student in Biochemistry, Marudu Pandiyar College, Thanjavur, Tamilnadu, India. \\ ${ }^{2}$ Assistant Professor in Biochemistry, ACPM Medical College, Dhule, Maharashtra, India. \\ ${ }^{1}$ Mphil student in Biochemistry, Marudu Pandiyar College, Thanjavur, Tamilnadu, India. \\ ${ }^{3}$ B.sc MLT Student, Shri Sathya Sai Medical College, Ammapettai, Chennai, India. \\ *Corresponding author's E-mail: ilanbiochemistry@gmail.com
}

Received: 14-02-2021; Revised: 22-04-2021; Accepted: 30-04-2021; Published on: 15-05-2021.

\section{ABSTRACT}

Cynodon dactylon occupies a key position in ethno medicinal practices and traditional medical knowledge systems (Ayurveda, Unani, Nepalese, and Chinese). Cynodon dactylon possess immense medicinal value and may be applied both externally as well as internally. The plant possesses antiviral and antimicrobial activity. A group of 36 adult Swiss albino rats weighing $100-150 \mathrm{~g}$ were purchased from Rainbow Institute kattumannargudi and brought to the laboratory in large sized microlon cages. Fresh dry husk was used as bed material. They were fed with commercial pellet diet from Sai Durga feed and foods, Bangalore and tap water ad-libitum. They were maintained at room temperature under standard laboratory conditions. In these medicinal plants, these are present/absent as a steroids, alkaloids, flavonoids, diterpenes, glycosides, tannins and phenols, xanthoproteins, gums and mucilage, fixed oils and fats, saponins, phytosterols, volatile oils, proteins and free amino acids etc. these are easily identified by biochemical analysis (qualitative). Qualitative Photochemical Screening on extracts of Cynodon dactylon gives better result on extract from Albino Rats. We are concluding that, biochemical studies by using Cynodon dactylon on Albino rats are very effective. Further studies are being carried out to characterize and explore the biological activity of the compounds present in the extract.

Keywords: Cynodon dactylon, Phytochemical analysis, Albino Rats, soxhlet apparatus.

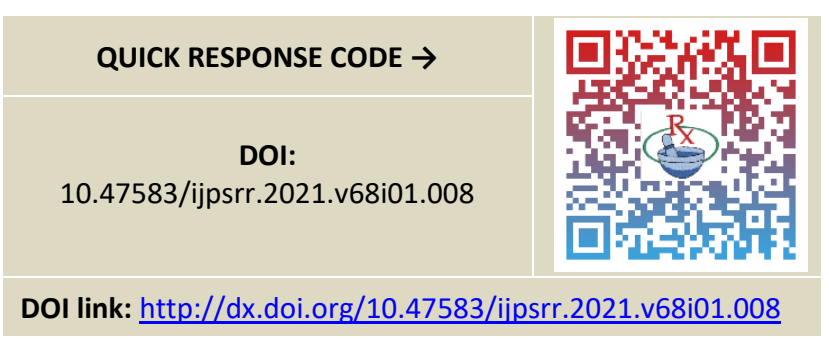

\section{INTRODUCTION}

ndia has a rich heritage of traditional knowledge and is home to several important time-honored systems of health care like Ayurveda, Siddha and Unani. It has been estimated that the proportion of medicinal plants in India $(7,500$ of the 17,000 higher plant species are medicinal plants) is higher than any country of the world with respect to the existing flora of that respective country ${ }^{\mathbf{1 , 2}}$.

Cynodon dactylon is hardy, perennial grass, very variable, with long rapid growing, creeping runner or stolons, rooting at nodes, forming a dense tuft on the surface of the soil, runners sometimes $20 \mathrm{~m}$ long, $2-6 \mathrm{~mm}$ broad, flat or sometimes folded or convolute; inflorescence on clums $15 \mathrm{~cm}$ to $1 \mathrm{~m}$ tall consisting of 2-12 spikes arranged star like at apex of stem; spikes $2.5-10 \mathrm{~cm}$ long with numerous spikelets, arranged in 2 rows on one side of spike; spikelets flat, 2-2.5mm long, awnless, with 1 floret; glumes unequal, the upper longer and one third to three fourth length of floret. The grass grows throughout India ascending up to a height above sea level of $8000 \mathrm{ft}$. It is a hardy perennial grass with creeping clums, rooting at nodes and forming spreading mats on the surface of the soil. It is abundant on road sides and paths, and readily takes possession of any uncultivated area. It flowers nearly throughout the year. ${ }^{3}$

Cynodon dactylon occurs on almost all soil types especially in fertile soil. e.g. loamy soil. It is common in disturbed areas such as gardens, roadsides, overgrazed, trampled areas, uncultivated lands, localities with high levels of nitrogen, and is often found in moist sites along rivers. It is suitable for cultivation under dry land conditions. It is widely distributed in southern African countries, in biomes such as grassland, Savanna, Nama-Karoo and Fynbos 4,5

The main goal of our present study has been extended to evaluate the effect of Cynodon dactylon on various biochemical parameters (Phytochemical analysis) in rats.

\section{MATERIALS AND METHODS}

For the present study, the mature green leaves of Cynodon dactylon belongs to family of Poaceae were collected from in and around area of Thanjavur District, Tamil Nadu, South India. The plant was identified with the help of Manual of Tamil Nadu and Karnatic flora. ${ }^{6}$

\section{Preparation of leaf powder}

The Cynodon dactylon was collected washed, cut into small pieces and dried at room temperature (390C) for two weeks and made into powder by using mixture for further analysis. 


\section{Preparation of plant extract}

Extraction is a process, to separate or isolate the secondary metabolites from plant material. It is basically two types i.e. heat and cold extraction. Heat extraction has some advantage over cold extraction like time consistency and also no contamination by microbes. An apparatus called soxhlet did heat extraction. 100g of the plant leaf powder were packed into the thimble of a soxhlet apparatus. The ratio of the plant powder and solvents were maintained at $1: 4$.

\section{EXPERIMENTAL DESIGN}

Animals are acting as good models for numerous experiments, which are carried to bring the beneficial effects on human population; this formed the basis for selection.

A group of 36 adult Swiss albino rats weighing $100-150 \mathrm{~g}$ were purchased from Rainbow institute kattumannargudi and brought to the laboratory in large sized microlon cages. Fresh dry husk was used as bed material. They were fed with commercial pellet diet from Sai Durga feed and foods, Bangalore and tap water ad-libitum. They were maintained at room temperature under standard laboratory conditions.

\section{Phytochemical Study}

The ethanol solvent was used for the extraction of plant powder through the soxhlet apparatus to test the presence or absence of alkaloids flavonoids, steroids, etc. The predigested dried explants were also extracted by the above procedure. The methods of preliminary phytochemical analysis have been presented. The mark root after the ethanol extraction was dried and extracted with $100 \mathrm{ml}$ of ethanol $\left(77.5-78.5^{\circ} \mathrm{C}\right)$ by continuous hot percolation, until the extraction was completed. After the completion of extraction, the extract was filtered and the solvent was removed by distillation under reduced pressure. A dark green coloured residue was obtained.

\section{Qualitative Phytochemical Analysis}

The plants are valuable sources of industrially important natural products, which include flavours, fragrances, essential oils, pigments, sweeteners, feed stocks and pharmaceuticals. These chemical compounds belong to a metabolic group collectively referred to as secondary metabolites. They do not participate in vital metabolic functions but appear to serve as a chemical interface between the producing plant and its surrounding environments. In this medicinal plants, these are present/absent as a steroids, alkaloids, flavonoids, diterpenes, glycosides, tannins and phenols, xanthoproteins, gums and mucilage, fixed oils and fats, saponins, phytosterols, volatile oils, proteins and free amino acids etc. these are easily identified by biochemical analysis (qualitative).

\section{Test for Steroids}

Salkowski's Test: The sample was extracted with alcohol. To which few drops of concentrated sulphuric acid was added and shaken well and kept in room temperature it gives red colour.

(i) Libermann-Burchard's Test:

The extract sample was taken in a test tube. To which few drops of acetic anhydride and $1 \mathrm{ml}$ of concentrated sulphuric acid were added along the sides of test tube. The brown ring was formed at the junction of two layers.

\section{Tests for Flavonoids}

$5 \mathrm{ml}$ of alcoholic extract (corresponding to $1 \mathrm{~g}$ of plant material) was treated with a few drops of concentrated hydrochloric acid and magnesium turnings $(0.5 \mathrm{~g})$. The presence of flavonoids was identified by the development of magenta-red color developed within 3 minutes.

\section{Tests for Alkaloids}

A small quantity of extracts was added to ammonia solution, shaken well and then extracted with alcohol. Alcohol solution was then extracted with diluted hydrochloric acid. Acid layer was used for following chemical test for alkaloids.

Mayer's test : The acid layer was taken in a test tube. To which few drops of Mayer's reagent (Potassium Mercuric Chloride) was added and mixed well. Creamy precipitate was formed.

Wagner's test : The acid layer was taken in a test tube. Then few drops of Wagner's reagent (Solution of iodine in Potassium iodide) was added and mixed well. A reddish brown colour precipitate was formed.

Hager's test : The acid layer was taken in a test tube. To which few drops of Hager's reagent (Saturated solution of Picric acid) was added. Yellow precipitate was formed.

Dragandorff's test : The acid layer was taken in a test tube. To which few drops of Dragandorff's reagent (Solution of Potassium Bismuth lodide) was added. Reddish brown precipitate was formed.

\section{Test for Carbohydrates}

Few drops of Molisch's reagent was added to $2 \mathrm{ml}$ of test solution and mixed well. About $1 \mathrm{ml}$ of concentrated sulphuric acid was added along with sides of test tube and brown colour was observed at the junction of two liquids.

\section{Test for Tannins and Phenols}

Small quantity of $50 \%$ alcohol extract was dissolved in water and ferric chloride solution (5\%) was added. Blue colour was appeared, which indicates the presence of tannins and phenols.

\section{Test for Gums and mucilages}

About $10 \mathrm{ml}$ of extract was slowly added to $25 \mathrm{ml}$ of absolute alcohol under constant stirring. Precipitation 
indicates the presence of gums and mucilages.

\section{Test for fixed oils and fats}

A drop of alcohol extract was pressed in between two filter papers and kept undisturbed state. An oils stain on the paper indicates the presence of oils and fats.

\section{Test for Phytosterols}

The extract was mixed with alcoholic potassium hydroxide till complete saponification takes place. It was diluted with distilled water.

The alcohol extract was evaporated and the residue was subjected to LB (Libermann-Burchard's) test. Appearance of red from orange colour indicates the presence of phytosterols.

\section{Test for Saponins}

About $1 \mathrm{ml}$ of the extract was dissolved in $20 \mathrm{ml}$ of water and shacked in a graduated cylinder for 15 minutes. Formation of $1 \mathrm{~cm}$ layer of foam indicates the presence of saponins.

\section{Test for Volatile oils}

$50 \mathrm{~g}$ of powdered material were taken in a volatile oil estimation apparatus and subject it to hydro distillation, for the detection of volatile oil. Distillate was collected in the graduated tube, in which the aqueous portion was automatically separated from the volatile oil, it was present in the drug, and returned back to the distillation flask.

\section{Proteins and free amino acids}

(i) Biuret test : Dissolved small quantities of alcohol extract in a few $\mathrm{ml}$ of water and the solution subjected to Biuret test, pink-purple colour indicates the presence of proteins.

(ii) Ninhydrin test : Dissolved small quantities of alcohol extract in a few $\mathrm{ml}$ of Ninhydrin reagent and then heated. Formation of purple colour indicates the presence of amino acids.

Xanthoproteic test : Dissolved small quantities of alcohol extract in a few drops of concentrated nitric acid and then heated. Added $40 \%$ of sodium hydroxide solution form yellow colour, which turns into orange colour, which indicates the presence of amino acids.

\section{RESULTS}

The phytochemical constituents of the Cynoden dactylon plant were analyzed and the results were given here.

Table 1: Qualitative Phytochemical Screening on extracts of Cynodon dactylon

\begin{tabular}{|c|c|c|c|}
\hline S.No & Compound & Test applied / Reagent used & Observation \\
\hline \multicolumn{4}{|c|}{ Tested } \\
\hline 1 & Alkaloids & $\begin{array}{l}\text { A] Mayer's } \\
\text { B] Wagner's } \\
\text { C] Hagner's } \\
\text { D] Dragndorff's test }\end{array}$ & $\begin{array}{l}++ \\
+++ \\
+++ \\
++\end{array}$ \\
\hline 2 & Flavonoids & $\mathrm{HCl}$ and magnesium turnings & ++ \\
\hline 3 & Carbohydrate & Molisch's test & ++ \\
\hline 4 & Tannins \& Phenol & $\begin{array}{l}\text { A] } 10 \% \text { Lead acetate } \\
\text { B] } \mathrm{Fecl}_{3}\end{array}$ & $\begin{array}{l}+++ \\
++\end{array}$ \\
\hline $\begin{array}{l}5 \\
6\end{array}$ & $\begin{array}{l}\text { Test for Steroids } \\
\text { Gums \&Mucilages }\end{array}$ & $\begin{array}{l}\text { A] Salkowski's Test } \\
\text { B] Libermann-Burchard's Test Alcoholic precipitation }\end{array}$ & $\begin{array}{l}++ \\
++\end{array}$ \\
\hline 7 & Fixed oil \&Fats & Spot test & + \\
\hline 8 & Saponins & Foam test & - \\
\hline 9 & Phytosterols & LB test & ++ \\
\hline 10 & Volatile oil & Hydro distillation method & ++ \\
\hline 11 & Protein \& free amino acids. & $\begin{array}{l}\text { A] Biuret test } \\
\text { B] Ninhydrin test } \\
\text { C] Xanthoprotein test }\end{array}$ & $\begin{array}{l}+++ \\
++ \\
+\end{array}$ \\
\hline
\end{tabular}

\section{DISCUSSION}

Cynodon dactylon has been reported to have multidimensional pharmacological profile like antidiabetic, antihyperlipidemic, antiperoxidative antimicrobial, antiasthamatic and traditionally being used to cure rheumatism, conjunctivitis and gout. The present work has been undertaken to establish the various pharmacognostical parameters, which could serve as a measure of authentication and quality control of the crude drug. Various parameters like morphology, microscopy, chemo-microscopy, histochemistry, physico-chemical constants, numerical, fluorescence, secondary metabolites profiles of the leaves were studied and the salient diagnostic features were documented. Treatment of ulcers is a global problem and needs to be studied in detail. Based on these facts the present study was conducted to look at the antiulcer effects of $C$. dactylon leaf extract and 
flavonoid compounds of quercetin. Gastric ulcers were produced by oral administration of aspirin in albino rats. $C$. dactylon leaf extract quercetin and silver nanoparticle were given to see the response and this effect was compared with the ulcer healing drugs in market commonly used by ulcer patients.

The result of phytochemical screening of the aqueous and alcoholic extracts of $C$. dactylon revealed the presence of alkaloids, flavonoids, phytosterols, tannins and phenols. The plant extract of $C$. dactylon used for the present work was choosing on the basis of their medicinal values. The natural plant parts are having a wide range of medicinal properties like hepatoproductive, antimicrobial, diuretic, emollient, febrifuge, narcotic, purgative and sedative. Previous study in the naturally the ethanolic extracts of $C$. dactylon were subjected for phytochemical analysis. Phytochemical screening of the crude extract revealed the presence of alkaloids, cardiac glycosides, terpenoids, saponins, tannin, flavonoids and steroids but reducing sugars, carbonyl (aldehyde) and Phlobatanin show negative results. $^{7}$

In the present investigation alcoholic and aqueous extract of the plant showed the presence of alkaloids, flavonoids, phytosterols, tannins and phenols. The production of secondary metabolites by the plant cells growing in culture have been confirmed by several scientists. ${ }^{8} \mathrm{He}$ observed the production of indole alkaloids, ajmalicine in cell suspension culture of Catharanthus roseus.

These plants growing under natural conditions contain the spectrum of secondary metabolites such as phenols, flavonoids, quinones, coumarins, tannins and their glycosides, alkaloids, essential oils etc., the importance of these substance as microbial agents against the pathogen has been emphasized by several workers. In the present study, it was clearly understood that the alcohol extracted maximum amount of the different type of metabolites present in the $C$. dactylon.

The phytochemical analysis of the $H$. indicum and $C$. procumbens extracts showed the presence of tannins, alkaloids, flavonoids and phenolic compounds. Tannins have been found to form irreversible complexes with proline-rich proteins. ${ }^{9}$

The extract of ethanol solvent system was subjected to qualitative analysis of organic compounds such as ethanol extracts of explants was subjected to evaluate the phytochemical constituents. The present study carried out on the plant samples revealed the presence of medicinally active constituents. The phytochemical characters of the $C$. dactylon results investigated were summarized in Table -1 . Preliminary phytochemical analysis revealed the presence of alkaloids and saponins.

The other secondary metabolites like tannins, flavonoids, steroids, cardiac glycosides, etc. were present in trace amounts in some of the plants. It is not surprising that there are differences in the antimicrobial effects of plant species, due to the phytochemical properties and differences among species. It is quite possible that some of the plants that were ineffective in this study do not possess antibiotic properties, or the plant extracts may have contained antibacterial constituents, just not in sufficient concentrations so as to be effective. It is also possible that the active chemical constituents were not soluble in methanol or water. The drying process may have caused conformational changes to occur in some of the chemical constituents found in these plants (Parekh and Chandra, 2007). Our results finding that the previous phytochemical screening in the naturally growing Heliotropium indicum revealed the presence of secondary metabolites, ${ }^{9}$ steroidal alkaloids, Saponin and annin. ${ }^{10}$

The phytochemical screening and quantitative estimation of the percentage crude yields of chemical constituents of the plants studied showed that the leaves and stems were rich in alkaloids, flavonoids, tannins and saponins. They were known to show medicinal activity as well as exhibiting physiological activity. ${ }^{11}$

Steroids and tannins were found to be present in all the plants. It has been found that some of these investigated plants contained steroidal compounds. It should be noted that steroidal compounds are of importance and interest in pharmacy due to their relationship with such compounds as sex hormones.

This may be the reason the leaves of $C$. rutidosperma are used as vegetable for expectant mothers or breast feeding mothers to ensure their hormonal balance, since steroidal structure could serve as potent starting material in synthesis of these hormones. ${ }^{12}$

Other researchers have also reported the presence of terpenoids in $H$. indicum, and this plant is widely used in herbal medicine. E. heterophylla contains tannins and alkaloids and this conforms to the report. The latter also observed that some of the Euphorbia species including $E$. heterophylla are used as a purgative. They are also used in the treatment of cough, asthma and hay fever. ${ }^{13}$

C. dactylon possessed very high levels of alkaloids and flavonoids, and are employed in medicinal uses. The plants studied here can be seen as a potential source of useful drugs. Further studies are going on these plants in order to isolate, identify, characterize and elucidate the structure of the bioactive compounds. The antimicrobial activities of these plants for the treatments of the diseases as claimed by traditional healers are also being investigated.

\section{CONCLUSION}

Qualitative Photochemical Screening on extracts of Cynodon dactylon gives better result on extract from Albino Rats. We are concluding that, biochemical studies by using Cynodon dactylon on Albino rats are very effective. Further studies are being carried out to characterize and explore the biological activity of the compounds present in the extract. 


\section{REFERENCES}

1. Shiva MP. 1996. Inventory of Forestry Resources for Sustainable Management and Biodiversity Conservation New Delhi: Indus Publishing Company.

2. Kala CP, Dhyani PP, Sajwan BS. Developing the medicinal plants sector in northern India: challenges and opportunities. J Ethnobiol Ethnomed., 2006;2:32.

3. Agarwal, S.S and M. Paridhavi. 2007. Herbal Drug Technology, Universities press (India) Private Limited, Hyderabad, pp. 491-508.

4. Raghunathan, K and R. Mitra. Pharmacognosy of Indigenous Drugs, Central Council for Research in Ayurveda and Siddha, New Delhi. 1982;1:41-50.

5. Kokaski, C.J., Kokaski, R.J and F. J. Sima. Fluorescence of powered vegetable drugs under ultra violet radiation. J. Amer. Pharm. Assoc., 1958;47(10):715-717.

6. Kirtikar JD, Basu BD. 1994. "Indian Medicinal Plants" Vol-III $2^{\text {nd }}$ published by Lalit Mohan Basu; 49, Leader road, Allahabad, India, 2020p.

7. Venkatesan, D, C.M. Karrunakarn, S. Selva Kumar and P.T. Palani Swamy. Identification of Phytochemical Constituents of Aegle marmelos Responsible for antimicrobial Activity against Selected Pathogenic Organisms. Ethnobotanical Leaflets 2009;13:1362-72.

8. Ramawat, K.G. 1999. Secondary Metabolites in Biotechnology, Oxford - IBH Pub, New Delhi.

9. Boominathan, $\mathrm{M}$ and $\mathrm{V}$ Ramamurthy. Antimicrobial activity of Heliotropium indicum and Coldenia procumbens. J. Ecobiol., 2009;24(1):11 - 15.

10. Nadkarni KM. 1982. Indian Materia Medica, 3rd ed. Vol. 1. Bombay, Popular Book Depot, 432.

11. Sofowora A. Medicinal Plants and Traditional medicine in Africa. Published by John Wiley and Sons Ltd. 1st edition 1993;131: $168-171$.

12. Okwu DE. Phytochemicals and vitamin content of indigenous spices of South - Eastern Nigeria. J. Sustain. Agric. Environ. 2001;6: 30-34.

13. Burkill HM. 1994. The useful plants of West Tropical Africa vol 1. Families A-D.Royal Botanical Garden kew. pp. 441415.

\section{Source of Support: None declared.}

Conflict of Interest: None declared.

For any question relates to this article, please reach us at: editor@globalresearchonline.net New manuscripts for publication can be submitted at: submit@globalresearchonline.net and submit_ijpsrr@rediffmail.com 